\title{
Extending the Use of Hothouses through Heating with Residual Agricultural Biomass
}

\author{
Erol Murad ${ }^{1}$, Edmond Maican ${ }^{1}$, Cătălin Dumitrescu ${ }^{2}$ and Sorin-Ştefan Biriş ${ }^{1}$ \\ 1. Department of Biotechnical Systems, Politehnica University of Bucharest, Bucharest 060042, Romania \\ 2. Hydraulics and Pneumatics Research Institute (INOE-2000 IHP), Bucharest 040558, Romania
}

Received: June 19, 2015 / Accepted: August 08, 2015 / Published: September 30, 2015.

\begin{abstract}
The paper presents a study on increasing energy independence of a $200 \mathrm{~m}^{2}$ horticultural hothouse, by means of heating it with thermal energy from a TLUD (top-lit-up-draft) gasification procedure of local residual agricultural biomass, chopped at 10-50 mm and dried at $10 \%-15 \% \mathrm{RH}$ (relative humidity). It produces an average of $14 \%$ higt quality biochar. Hot-air heating system and forced circulation are equipped with two GAZMER 40/150G energetic modules, which are rechargeable, simple, safe, efficient and environmentally friendly. They can gasify chopped or pelletised biomass. To study the microclimate evolution, it was used a complex numerical model for a $200 \mathrm{~m}^{2}$ hothouse for growing vegetables. Simulated experiments were carried out for frosty days and, estimated, for the whole warming period. Each year $13.44 \mathrm{t}$ of biomass are consumed, resulting $1.78 \mathrm{t}$ of biochar which, when introduced in soil, produces a $-6.2 \mathrm{t} /$ year negative balance of $\mathrm{CO}_{2}$.
\end{abstract}

Key words: Hothouse, energy independence, TLUD, biochar, automat control, simulation.

\section{Introduction}

Essential to increase food security of Romania and to increase the health of the local population, is production of current consumption of vegetables throughout the winter. Winter vegetable production comes up to about $2 / 3$ out of unheated hothouses and the difference comes from industial type greenhouses. Due to competition in the global floricultural products, much of protected crop surfaces are allocated to flowers production, at the expense of production of vegetables. By reducing expenses necessary for heating hothouses and greenhouses, there can be produced more vegetables, with high quality and making an adequate profit both for producers and consumers.

To increase the life of the vegetable hothouses in order to increase vegetable production during the cold season, heating is required with simple thermal systems,

Corresponding author: Erol Murad, associate professor, research fields: automation and control systems, thermo-chemical gasification of biomass, modeling and simulation of unconventional processes. E-mail: erolmurad@yahoo.com. with low costs both in investment and operation. To reduce dependence on fossil fuels, with high $\mathrm{CO}_{2}$ emissions, currently the share of biomass for heating increases and, more rarely, biomass is used in cogeneration plants. Currently, it is used the biomass compacted into pellets, easy to carry and use as fuel, which required an extension of the use of this form of compaction. Burning is done with high superficial speeds which produces a higher concentration of PM that clogs the heat exchanger and pollute the environment. EU environmental legislation heavily restricts the concentration of PM (particulate matter), which leads to use of smoke filters or towards reducing the intensity of the thermal process. These in turn have the effect of price increases and a decrease of overall performance. For the production and transportation of pellets, an average of $200 \mathrm{kWh} / \mathrm{t}$ is consumed, which for a thermal/electric conversion efficiency of $25 \%$ represents about $16 \%-20 \%$ of the calorific energy of the compacted biomass. It is issued into the atmosphere, a large amount of $\mathrm{CO}_{2}$ from the production of 
electricity consumed and from the manufacturing of production equipment. The current price is $140-160 € / t$, slightly higher during the cold season [1].

Alternatively, a more ecological and economic alternative for thermal energy production needed to extend the useful life of hothouse with three months, or working like a greenhouse during the entire cold season, it is proposed and analyzed the use of local agricultural biomass residues at the level of current technology, with minimal mechanical processing [2-4]. Agricultural biomass, derived from fruit growing, viticulture and vegetable growing, is chopped at $10-50 \mathrm{~mm}$ and naturaly or forced dried at $10 \%-15 \%$ RH (relative humidity). Energy consumption from harvesting to use is $100 \mathrm{kWh} / \mathrm{t}$ less than in case of pelletization, and $50 \mathrm{kWh} / \mathrm{t}$ less for transport on distances under $30 \mathrm{~km}$. On average is $50 \mathrm{kWh} / \mathrm{t}$. This represents about $25 \%$ of the power consumption pelleting, or $4 \%-5 \%$ of the calorific power of used biomass. It is estimated that, this type of local fuel can be used at maximum $50 € / \mathrm{t}[2,5,6]$.

The most important reasons for using this type of biomass consists of ecological and economic advantages (lower consumption of fossil fuels), dependency reduction on unstable geopolitical entities. It also has the effect of encouraging the efficient use of local energy resources, innovation and employment growth in rural areas.

\section{Production of Heat with TLUD Energetic Modules}

To convert the local chopped biomass at $10-50 \mathrm{~mm}$, with $10 \%-15 \%$ moisture, in thermal energy, there can be used relatively low conversion efficiency combustion plants that produce a lot of PM (smoke), or thermo-chemical gasification can be applied, whic means lack of smoke and good efficiency. Conventional gasification plants are still relatively complex equipment, are senzitive to moisture and size of biomass, require highly trained operators, thus slowing down their use in agriculture. In order to reduce both the initial investment and the running operation costs, it is proposed the TLUD (top-lit-up-draft) process of gasification, which is tolerant and functional auto-adaptive to the particle size and moisture of biomass. It is also characterized by PM and CO very low emissions. Energetic modules for producing thermal energy based on the TLUD process have a simple design, are durable and safe under operation, and benefit from a cheaper price [4-7].

The TLUD gasification process is a reverse downdraft process that works in batch mode with reduced thermal load. Kinematics and dynamics of the gasification process are similar. At 25\%-30\% excess of air for gasification, not all carbon in biomass is reduced. Thereby at the end of the charge results $10 \%-15 \%$ charcoal, called biochar, with incorporated ash. Biochar has proven to be a valuable agricultural amendment to increase soil fertility. Considering biochar as a high usable value product, is obtained a thermal energy conversion efficiency of the completely gasified part of biomass of $92 \%-96 \%$, according to the operating conditions and characteristics of used biomass [5-8]. From the tests, it was found that, the LHV (lower heating value) of produced syngas is 3.5-4.5 MJ/ $\mathrm{Nm}^{3}$ which, summed with hot gas enthalpy at $500{ }^{\circ} \mathrm{C}$, leads to an available energy of 1.2-1.5 $\mathrm{kWh}_{\mathrm{th}} / \mathrm{Nm}^{3}[6,8-10]$.

In the reactor, the produced gas has a very low superficial velocity $v_{s}=0.03-0.06 \mathrm{~m} / \mathrm{s}$, providing a very low concentration of solid particles $\left(\mathrm{PM}_{2.5} \leq\right.$ $2.4 \mathrm{mg} / \mathrm{MJ}$ ), practically smokeless operation, far below standards imposed on the field. To operate with a high energy conversion efficiency and with minimum emissions, the minimum load of energetic modules is limited to $40 \%[6,8,10]$.

\section{Hot Air Heated Hothouse}

To determine the specific greenhouse heating with TLUD energetic modules, a quonset-metric type hothouse was chosen. It consists of 28 base modules having $6 \mathrm{~m}$, height $3 \mathrm{~m}$, pitch of $1.2 \mathrm{~m}$, and has a 
surface area on the ground of $200 \mathrm{~m}^{2}$ and a volume of $475 \mathrm{~m}^{3}$. It is covered with a double layer, inflatable, polyethylene, with high thermal resistance $[3,4]$.

The hothouse is heated with hot air, distributed through a flexible duct which has openings for the jets in the greenhouse space. Part of the inside air is recirculated and mixed with the outside air necessary for venting the greenhouse. The mixture is heated with an internal-flue HE (heat exchanger). This design eliminates the need for regular ventilation, whom is producing energy losses and decreases in temperature, which could prove harmful if not properly managed. Indoor crop consists of Vidra Romanian variety of tomato, for which experimental data for breath and perspiration are available. In order to protect the plants from contact with too warm air currents, the maximum temperature of the jets is limited to $40{ }^{\circ} \mathrm{C}$, which required a constant mass flow $\left(D_{a m}=2 \mathrm{~kg} / \mathrm{s}\right)$ of the air heating the greenhouse.

Fig. 1 shows the block diagram of a hothouse heated by two BGM (biomass-gasification-module) thermal modules. The two modules are connected to the burner mounted at the entrance of the internal-flue heat exchanger operating at a constant flow of heated air, and therefore, having a minimum efficiency of $85 \%$.

The experiment was simulated for a winter day temperatures within $-25-(-5){ }^{\circ} \mathrm{C}$, and constant indoor temperature $\left(T_{i}=10^{\circ} \mathrm{C}\right)$ and humidity $\left(U_{i}=70 \%\right)$. It has been determined the maximum thermal power required to heat the greenhouse: $P_{\text {incmax }}=58 \mathrm{~kW}$. It follows that, the maximum thermal power produced by a BGM module $\left(P_{B G M}\right)$ must be at least:

$$
P_{B G M n} \geq \frac{P_{i n c \max }}{\eta_{S C} N_{B G M}}=\frac{58}{0.85 \times 2}=34.12 \mathrm{~kW}
$$

where, $\eta_{S C}$ is minimum return of the heat exchanger, $N_{B G M}$ is number of modules.

There have been selected two GAZMER 40/150G energetic modules with a $400 \mathrm{~mm}$ reactor diameter and a hight of 1,500 mm. Reactor size was determined by the possibility of using agricultural biomass, whose bed density is between $200 \mathrm{~kg} / \mathrm{m}^{3}$ and $300 \mathrm{~kg} / \mathrm{m}^{3}$. Rated power of an energetic module is $40 \pm 5 \mathrm{~kW}$, with an average specific biomass consumption of 100 $\mathrm{kg} \cdot \mathrm{bm} /\left(\mathrm{m}^{2} \cdot \mathrm{h}\right)$.

\section{Simulated Experiments}

The block diagram in Fig. 1 shows the basic structure of the SERMGB27.DP simulation program, which is designed for hothouses microclimate. Simulated system consists of four subsystems: hothouse conditioning process, air heater, power unit with two BGM modules,

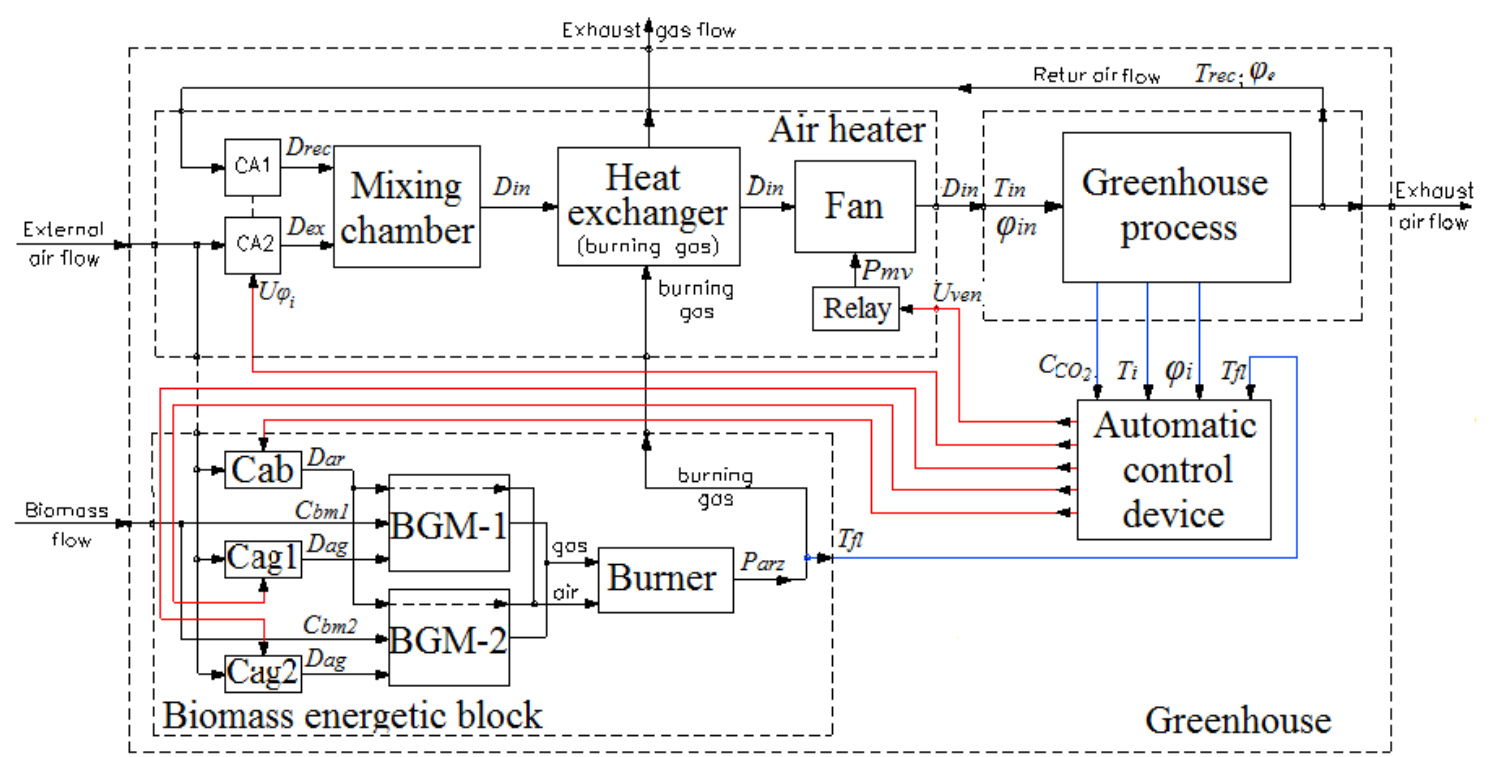

Fig. 1 Block diagram of a hothouse heated by TLUD energetic modules. 
subsystem for automatic control. To model the process of conditioning the hothouse in the block diagram have been highlighted the following specific parameters: input flow $D_{\text {in }}$ having temperature $T_{\text {in }}$ and relative humidity $\varphi_{i n}$; evacuated $D_{e v}$ and recirculated $D_{r e c}$ air flows.

BGM energy subsystem has two modules loaded with biomass, out of which every hour are consumed $C_{b m 1}$ and $C_{b m 2}(\mathrm{~kg} \cdot \mathrm{bm} / \mathrm{h})$, depending on the air flow for gasification $D_{a g}(\mathrm{~kg} \cdot \mathrm{air} / \mathrm{s})$, regulated by $C_{a g 1}$ and $C_{a g 2}$ flaps. The fuel gas produced is burnt with an air flow $D_{a r}$ adjusted with the flap $C_{a b}$. Flue gas enters the HE and transfers heat to the air that warms the hothouse $[3,4,11]$. Automatic control subsystem must be able to adjust key parameters that define the hothouse microclimate: indoor temperature $\left(T_{i}\right)$ and humidity $\left(U_{i}\right), \mathrm{CO}_{2}$ concentration $\left(C_{\mathrm{CO} 2}\right)$, as well as burner flame temperature $\left(T_{f l}\right)$. Setting the indoor temperature is done with a PID (proportional-integral-derivative) numerical algorithm, which develops a control parameter that changes the energy load of modules by varying gasification flow rates $\left(D_{a g}\right)$. Simultaneously, a dynamic optimization algorithm changes the flow of combustion air, so that the flame temperature $\left(T_{f 1}\right)$ to be as close as possible to the maximum value, thus maximizing the efficiency of burner [3, 4, 11-13].

\section{Results and Discussion}

Fig. 2 presents the result of an experiment with the $\varphi$ model of studied hothouse, for an average winter day, used to calculate heating requirements in Ilfov County, with a reference for the indoor temperature $r_{T i}=10^{\circ} \mathrm{C}$ by night and $12{ }^{\circ} \mathrm{C}$ during the daytime, and for an indoor relative humidity $r_{U i}=70 \%$.

Variations of the following parameters are displayed: $T_{e x}$-external temperature, $R_{a d s}$-solar radiation, $T_{i}, U_{i}$, $P_{t h}$-produced thermal power, $M_{\text {comb }}$ - biomass consumption. It is found that, $T_{i}$ has little variation compared to the reference, but $U_{i}$ varies somewhat more than the imposed reference. This shows that, the automatic control algorithm does not achieve full performance requirements.

Table 1 summarizes the simulation results of the heating for the cold season months when using chopped agricultural biomass, compared to using diesel. The first important resulted value is the annual consumption of biomass which is of $13,440 \mathrm{~kg} \cdot \mathrm{bm} /$ year, and which occupies a volume of $54 \mathrm{~m}^{3}$ in warehouse in 108 containers of $0.5 \mathrm{~m}^{3}$. Another valuable characteristic is the average specific consumption of biomass for heating during winter $c_{b m s}=13.2$ $\mathrm{kg} \cdot \mathrm{bm} /(\mathrm{K} \cdot$ day $)$. With this value, can be quickly and accurately size heating systems for greenhouses and hothouses. From biomass gasification in BGM results $1,780 \mathrm{~kg}$ of biochar each year, that can harness $200 € / \mathrm{t}$, or that can be incorporated as amendment for the soil in solarium with a negative annual $\mathrm{CO}_{2}$ balance of $-6.2 \mathrm{t} / \mathrm{year}$.

Average specific cost of biomass for hothouse heating during winter is $0.672 € / \mathrm{m}^{2} \cdot$ month, which is about 20 times lower than with diesel and four times lower than with pellets. This clearly shows the economic efficiency of minimally processed local agricultural biomass into gas-producing TLUD.

\section{Conclusions}

By heating hothouses with thermal generators based on TLUD gasification process, local agricultural biomass residues, minimally processed, can be used economically and environmentally efficient at a price of $50 € / \mathrm{t}$. The specific costs for heating are four times lower than for pellets and 20-fold lower than for diesel fuel. Analyzed hothouse can be used as greenhouse throughout the entire cold season with a consumption of 13.5 tons biomass, from which results 1.8 tonnes of biochar that can be sold as charcoal, or that can be incorporated as amendment for the soil in solarium with a negative annual $\mathrm{CO}_{2}$ balance of -6.2 $\mathrm{t} /$ year.

Biomass hothouse heating in the analyzed version is done with virtually no emissions of toxic effluents, pollutants, and with negative balance of atmospheric carbon. 


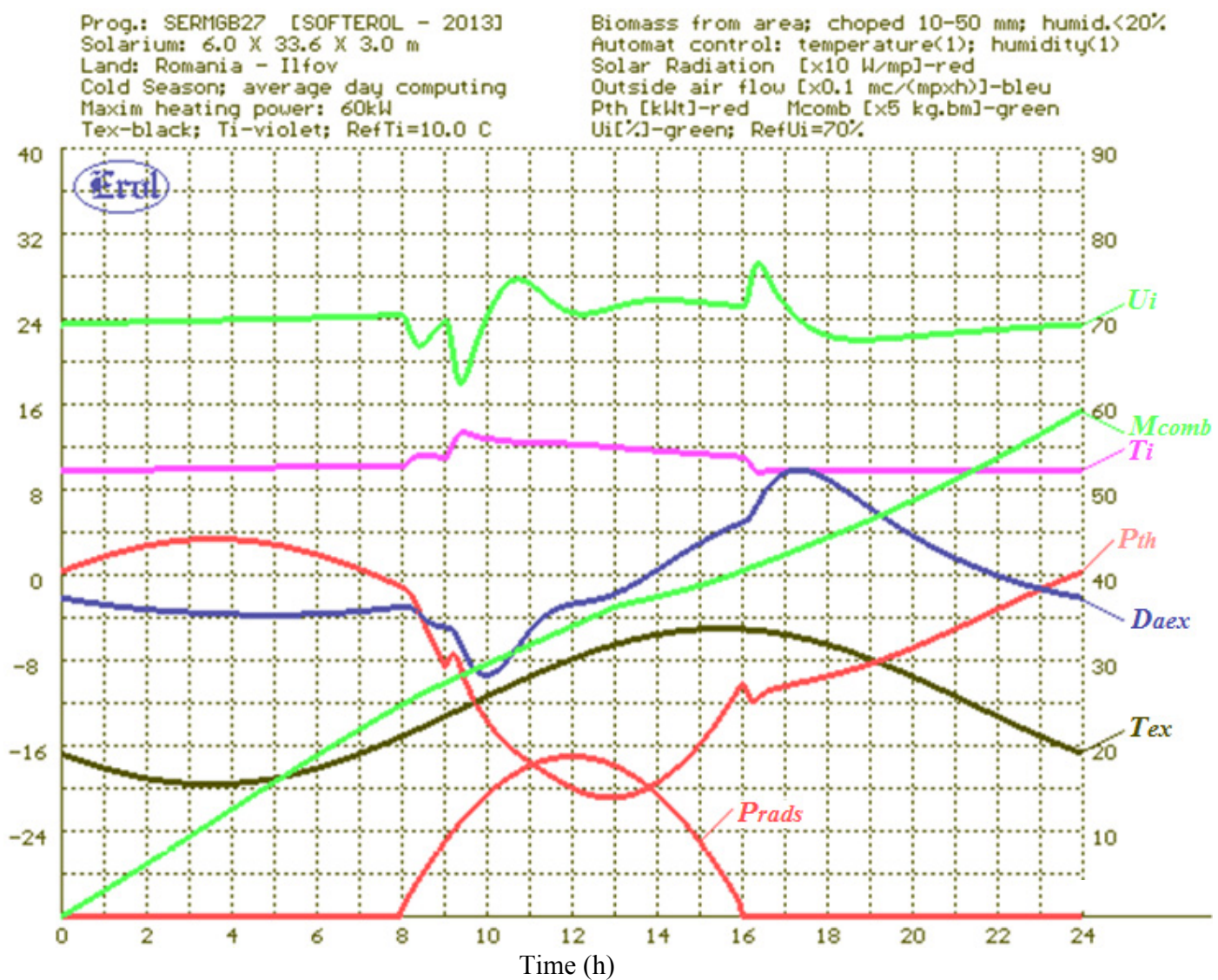

Fig. 2 The evolution of a hothouse microclimate in a winter average day.

Table 1 Simulated experimental results.

\begin{tabular}{|c|c|c|c|c|c|c|c|c|}
\hline Parameter & Month & Oct. & Nov. & Dec. & Jan. & Febr. & Mar. & $\begin{array}{l}\text { Cold } \\
\text { season }\end{array}$ \\
\hline Heating period & day/month & 15 & 30 & 31 & 31 & 28 & 15 & 150 \\
\hline Average outside temp. & grade $\mathrm{C}$ & 7.00 & 5.20 & -0.10 & 1.20 & 5.60 & 7.00 & 3.71 \\
\hline Indoor average temp. & grade $\mathrm{C}$ & 10.50 & 10.50 & 10.50 & 10.50 & 10.50 & 10.50 & 10.50 \\
\hline Average required heating & $\mathrm{K} \cdot$ day/month & 52.50 & 159.00 & 328.60 & 288.30 & 137.20 & 52.50 & $1,018.10$ \\
\hline Biomass specific consumption & $\mathrm{kg} \cdot \mathrm{bm} /(\mathrm{K} \cdot$ day $)$ & 13.20 & 13.20 & 13.20 & 13.20 & 13.20 & 13.20 & 13.20 \\
\hline Biomass consumption & $\mathrm{t} \cdot \mathrm{bm} / \mathrm{month}$ & 0.693 & 2.099 & 4.338 & 3.806 & 1.811 & 0.693 & 13.439 \\
\hline Biochar production & $\mathrm{t} \cdot \mathrm{bc} / \mathrm{month}$ & 0.092 & 0.278 & 0.575 & 0.504 & 0.240 & 0.092 & 1.781 \\
\hline Price - chopped agric. biomass & $€ / \mathrm{t}$ & 50.00 & 50.00 & 50.00 & 50.00 & 50.00 & 50.00 & 50.00 \\
\hline Price_-biochar as amendment & $€ / \mathrm{t}$ & 200.00 & 200.00 & 200.00 & 200.00 & 200.00 & 200.00 & 200.00 \\
\hline Cost biomass for heating & $€ /$ month & 34.65 & 104.94 & 216.88 & 190.28 & 90.55 & 34.65 & 671.95 \\
\hline Revenue capitalization biochar & $€ /$ month & 18.36 & 55.62 & 114.94 & 100.85 & 47.99 & 18.36 & 356.13 \\
\hline Net cost heating fuel & $€ /$ month & 16.29 & 49.32 & 101.93 & 89.43 & 42.56 & 16.29 & 315.81 \\
\hline Specific cost—biomass heating & $€ /\left(\mathrm{m}^{2} \cdot \mathrm{month}\right)$ & 0.173 & 0.525 & 1.084 & 0.951 & 0.453 & 0.173 & 0.672 \\
\hline Net cost—biomass heating & $€ /\left(\mathrm{m}^{2} \cdot \mathrm{month}\right)$ & 0.081 & 0.247 & 0.510 & 0.447 & 0.213 & 0.081 & 0.316 \\
\hline Diesel consumption for heating & $\mathrm{L} \cdot \mathrm{mt} /(\mathrm{kg} \cdot \mathrm{bm})$ & 0.35 & 0.35 & 0.35 & 0.35 & 0.35 & 0.35 & 0.35 \\
\hline Diesel—monthly cost & $€ /$ month & 327.03 & 990.44 & $2,046.92$ & $1,795.88$ & 854.65 & 327.03 & $6,341.96$ \\
\hline Specific cost—diesel heating & $€ /\left(\mathrm{m}^{2} \cdot \mathrm{month}\right)$ & 1.64 & 4.95 & 10.23 & 8.98 & 4.27 & 1.64 & 6.34 \\
\hline $\mathrm{CO}_{2}$ balance with carbon sequestration & $\mathrm{t}\left(\mathrm{CO}_{2}\right) /$ month & -0.32 & -0.97 & -2.00 & -1.76 & -0.84 & -0.32 & -6.20 \\
\hline
\end{tabular}


A comprehensive program was developed to simulate the hothouse microclimate, SERMGB27.DP, the model also including the TLUD process thermal generators model. Automatic control algorithm for hothouse climate has been verified, which ensures both maintaining optimal microclimate parameters and automatic control of heat generator. The model developed for simulation is a strong basis for research and development in the field, being open source.

Results require an experimental validation on a real hothouse, both for confirming the results of simulated experiments and to determine the real economic aspects derived from extending the useful life during cold season.

Intensive use of local agricultural biomass resources for the production of heat and biochar leads to an increase in the use of labor in rural areas, to a better use of local resources, and to a higher living standards and sustainable development in the area.

\section{References}

[1] Risovic, S., Dukic, I., and Vukovic, K. 2008. "Energy Analysis of Pellets Made of Wood Residues." Croat Journal for Engineering 29 (1): 95-108.

[2] Daugherty, E. C. 2001. "Biomass Energy Systems Efficiency Analized trough a Life Cycle Assesement." Master's of Science thesis, LUND University.

[3] Murad, E., Maican, E., Haraga, G., and Biriş, Ş. S. 2011. "Greenhouse Module Heating with Biomass." Presented at the International Symposium, Horticulture-Science, Quality, Diversity, Harmony, Iasi, Romania.

[4] Murad, E., Maican, E., Biriş, S. S., and Vlăduț, V. 2011. "Heating Greenhouses with TLUD Biomass Energy Modules." Presented at the 3rd International Conference on Research People and Actual Tasks on Multidisciplinary Sciences, Lozenec, Bulgaria.

[5] Murad, E., Achim, G., and Rusănescu, C. 2012. "Energy Recovery from Biomass and Organic Orchards Cuts, Scientific Communications Session.” Research and Development Institute for Industrialization and Marketing of Horticultural Products-ICEDIMPH-HORTING.

[6] Murad, E., and Dragomir, F. 2012. "Heat Generators with TLUD Gasifier for Generating Energy from Biomass a Negative Balance of $\mathrm{CO}_{2}$." In Proceedings of the International Conference-HERVEX-2012, 440-7.

[7] Murad, E., Culamet, A., and Zamfiroiu, G. 2011. "Biochar- Economically and Ecologically Efficient Technology for Carbon Fixing." Presented at the 2011 International Salon of Hydraulics and Pneumatics-HERVEX, Calimanesti-Caciulata, Romania.

[8] Mukunda, H. S. 2010. "Gasifier Stoves-Science, Technology and Field Outreach." Curent Science 98 (5): 627-38.

[9] Reed, T. B., and Das, A. 1988. "Handbook of Biomass Downdraft Gasifier Engine Systems." U.S Department of Energy.

[10] Varunkunar, S. 2012. "Packed Bed Gasification-Combustion in Biomass Domestic Stove and Combustion Systems." Ph.D. thesis, Department of Aerospace Engineering Indian Institute of Science.

[11] Ramírez-Arias, A., Rodríguez, F., Guzmán, J. L., Arahal, M. R., Berenguel, M., and López, J. C. 2005. "Improving Efficiency of Greenhouse Heating Systems Using Model Predictive Control." Copyright (C) 2005 IFAC (International Federation of Automatic Control).

[12] Murad, E. 2005. "Optimisation of Biomass Gasification Load Regime." Presented at the CIEM (International Conferece Energie-Mediu) 2005, Bucureşti, Romania.

[13] Murad, E., Dumitrescu, C., Haraga, G., and Dumitrescu, L. 2012. "Pneumatic Measurement of the Biomass Consumption for TLUD Generator." Presented at the International Conference HERVEX 2012, Călimăneşti, Romania. 